\title{
DESIGN DE JOIAS COM MATERIA-PRIMA BRASILEIRA E CONCEITO ART NOUVEAU
}

\author{
Fabiane Lima Ledel1 \\ Maria da Graça Portella Lisboa 2
}

Edir Lúcia Bisognin 3

\begin{abstract}
RESUMO: O projeto proposto, inspirado no estilo Art Nouveau, apresenta a criação de uma coleção de joias em que as peças das linhas: Lé Metropolitain, Petit Palais e Villa Majorelle remetem aos elementos arquitetônicos e do mobiliário urbano da época. Em que os elementos orgânicos e as formas assimétricas foram adaptados a tendência de mercado atual, visando, assim, atender o público feminino. O metal foi o material escolhido como base para a criação da coleção, pois remete ao ferro forjado, utilizado nas obras de referência. Outros temas importantes abordados no decorrer do texto são a valorização da matéria-prima nacional, como as gemas e o capim dourado, bem como a questão ambiental relacionada aos processos de produção e os aspectos simbólicos valorizados na estética contemporânea.
\end{abstract}

Palavras-chave: Joia. Design. Art Nouveau.

ABSTRACT: The proposed project, inspired by the Art Nouveau style shows the creation of a jewelry collection, in which pieces of the lines: Le Metropolitain, Petit Palais and Villa Majorelle refer to architectural elements and furniture of the time. Where the organic elements and asymmetric forms were adapted to current market trends in order to attend the female audience. The metal was chosen as reference material. Other important topics covered throughout the text are the enhancement of national raw materials, such as gems and golden grass, as well as environmental issues related to production processes and symbolic aspects valued in contemporary aesthetics.

Palavras-chave: Jewelry. Design. Art Nouveau.

\footnotetext{
1 Mestre em engenharia de Produção, Centro Universitário Franciscano, Curso de Design. fabi_zita_@hotmail.com

2 Mestre em engenharia de Produção, Centro Universitário Franciscano, Curso de Design. mgporlisboa@gmail.com

${ }^{3}$ Mestre em engenharia de Produção, Centro Universitário Franciscano, Curso de Design. Edir@unifra.br
}

ReLAInEP - Revista Latino-America de Inovação e Engenharia de Produção, Curitiba, PR, Brasil, v. 3, n. 4, p. 9-24, 2015. 


\section{ReLAInEP}

RESUMEN: El proyecto propuesto es inspirado en el estilo Art Nouveau, características de la creación de una colección de joyas en el que las partes de las líneas: Lé Metropolitain, Petit Palais y Villa Majorelle se refieren a elementos arquitectónicos y mobiliario urbano de la época. Cuando los elementos orgánicos y formas asimétricas se adaptaron a la tendencia actual del mercado, con el objetivo de este modo cumplir con el público femenino. El metal fue el material elegido como base para la creación de la colección ya que se refiere a hierro forjado, que se utiliza en trabajos de referencia. Otros temas importantes tratados en el texto son la apreciación de la materia prima local, como las gemas y la hierba de oro, y las cuestiones ambientales relacionadas con los procesos de producción y los aspectos simbólicos valorados en la estética contemporánea.

Palabras clave: Bijou. Diseño. Art Nouveau.

\section{INTRODUÇÃO}

O presente projeto procurou desenvolver uma coleção de joias inspiradas nos elementos estruturais e decorativos utilizados na arquitetura Art Nouveau como referência para o desenvolvimento de um produto para a contemporaneidade no mercado joalheiro. A inspiração para a criação deste projeto utiliza princípios abordados pelos percussores do estilo Art Nouveau, que surgiu no final do século XIX, influenciado pelos ideais do movimento “Art and Crafts", trazendo mudanças radicais para o campo artístico e cultural.

Para os percursores desse estilo, diferente do trabalho artesanal, a máquina não proporcionava a liberdade de criação e da forma. Motivados pelo espírito de renovação, os artistas e designers acreditavam que, para se aproximar de uma arte moderna, era necessário romper com estilos clássicos ultrapassados. Essas ideias tornaram-se uma meta, que foi seguida por diversos artistas em várias partes do mundo. Apesar do curto período de duração, o Art Nouveau difundiu-se pela Europa e América, recebendo diversos títulos e criando características próprias onde se manifestava.

O tema do estilo Art Nouveau (MARKOWITZ; WARD, 2008; SANDROLINE et al., 2011) é o universo natural no qual formas fitomórficas e biomórficas inspiraram artistas na criação de móveis, joias, estruturas, decoração de interiores, pintura, escultura e artes gráficas, entre outros. As linhas delicadas, ondulantes e estilizadas atingiram rapidamente um patamar internacional nos diversos setores das artes decorativas e aplicadas, mas foi na arquitetura que o Art Nouveau obteve sua expressão máxima. O privilégio da forma, o desenho e o emprego

ReLAInEP - Revista Latino-America de Inovação e Engenharia de Produção, Curitiba, PR, Brasil, v. 3, n. 4, p. 8-23, 2015. 


\section{ReLAInEP}

de novos materiais, como vidro e o ferro, contribuíram para a consolidação da arte moderna e do design, redefinindo conceitos e novas possibilidades de criação.

Observa-se, na literatura revisada, que nesse período o design fez diferença, pois o valor dos produtos passou a ser associado ao desenho diferenciado e não apenas nos materiais com os quais eram fabricados. E, ainda hoje, a boa forma, aliada à função, é a responsável por gerar desejo de consumo nas pessoas. Assim, por meio de análises e pesquisas bibliográficas, utilizou-se dos elementos da arquitetura Art Nouveau como referência para a concepção de um produto que valorizou a matéria-prima nacional e o meio ambiente.

\section{REVISÃO BIBLIOGRÁFICA}

Nesta seção serão abordados os seguintes tópicos: (i) design de joias e o mercado joalheiro; (ii) breve história da joalheria no mundo; (iii) aspectos sociológicos e sustentabilidade do produto e; (iv) aspectos simbólicos da joia.

\subsection{Design de Joias e o Mercado Joalheiro}

Há algumas décadas, o Brasil não possuía um design próprio no setor joalheiro. As inspirações decorriam do que era designado pelo mercado internacional. Não havia incentivo e tão pouco preocupações em valorizar a matéria-prima local e instituir uma identidade nacional ao produto. Para o presidente do IBGM (Instituto Nacional de Metais e Pedras Preciosas), Hécliton Santini Henriques, o design de joias no Brasil fortaleceu-se a partir da metade da década de 90, após o Plano Real, quando o mercado voltou a crescer e a concorrência com a mercadoria importada ficou mais ativa. Atualmente, o Brasil participa ativamente do mercado mundial, estando entre os 20 países produtores de joias de ouro e ocupa o $13^{\circ}$ lugar no seu consumo. Os principais polos industriais no Brasil estão localizados no Rio Grande do Sul, São Paulo, Minas Gerais, Rio de Janeiro, Pará e Bahia.

O design é o emprego econômico de meios estéticos no desenvolvimento de produtos, de modo que estes atraiam a atenção dos possíveis compradores, ao mesmo tempo em que otimizem valores de uso dos produtos comercializados (LÖBACH, 2012). A indústria brasileira abriu portas para a criatividade, a originalidade e a liberdade de criação quando

ReLAInEP - Revista Latino-America de Inovação e Engenharia de Produção, Curitiba, PR, Brasil, v. 3, n. 4, p. 8-23, 2015. 


\section{ReLAInEP}

tornou possível a exploração de materiais típicos do Brasil, valorizando as gemas e metais preciosos, além da grande diversidade de matéria-prima.

O design inovador e a busca por um diferencial na joia (SIMONI; RABINO; ZANNI, 2010), com a mistura de materiais inusitados, tornaram o mercado capaz de concorrer com produtos importados, servindo de inspiração para designers e estilistas no mundo. Com a era tecnológica e digital, surgiu a necessidade de capacitar um profissional designado ao planejamento e criação de joias, pensando nos materiais e processos que implicarão na sua materialização. Neste contexto, encontra-se a moda envolvida com a joalheria. Este setor vem investindo em coleções sazonais, aliando a moda ao vestuário com coleções inovadoras que acompanham o ritmo das tendências. A aproximação da joalheria com o universo da moda permite que o mercado cresça, explore temas, formas, cores, abrindo um leque de opções para o setor de joias.

No mercado comercial, as joalherias consagradas aliam o design a elementos da moda e vestuário, utilizando-os como fonte de inspiração para suas coleções. Assim, como a moda transforma-se a cada estação, o setor joalheiro foca nesse caminho que está em constante mutação e que proporciona movimentação para o setor.

Constata-se, na sociedade capitalista, que a grande concorrência leva as empresas a criar novos produtos a todo o momento, o que oportuniza o trabalho do designer que, com criatividade e mistura de materiais, tenta inovar a cada projeto criado para conquistar o consumidor.

A literatura revisada (LEDEL, 2011) mostra que os bens de consumo de alto valor tecnológico, como celulares, câmeras digitais, entre outros, são os maiores concorrentes do mercado joalheiro no mundo. A partir de pesquisas, foi constatado que as exportações e vendas no setor da indústria de folheados e bijuterias sofreram grande acréscimo. Esses produtos competem com produtos de qualidade, em razão do design diferenciado, a mistura de materiais e preços acessíveis.

\subsection{Design de Joias e o Mercado Joalheiro}

O estilo Art Nouveau trouxe para as joias formas orgânicas, traços leves e linhas ondulantes. Nas joias, o valor dos metais e das pedras preciosas tinha menor importância perante o design único característico do estilo. René Lalique foi o pioneiro na técnica com

ReLAInEP - Revista Latino-America de Inovação e Engenharia de Produção, Curitiba, PR, Brasil, v. 3, n. 4, p. 8-23, 2015. 


\section{ReLAInEP}

vidro e também o responsável por abrir os horizontes do setor joalheiro, ao utilizar e explorar materiais distintos para a produção de suas joias. A Figura 1 ilustra o estilo Art Nouveau.

Figuras 1 - Estilo Art Nouveau
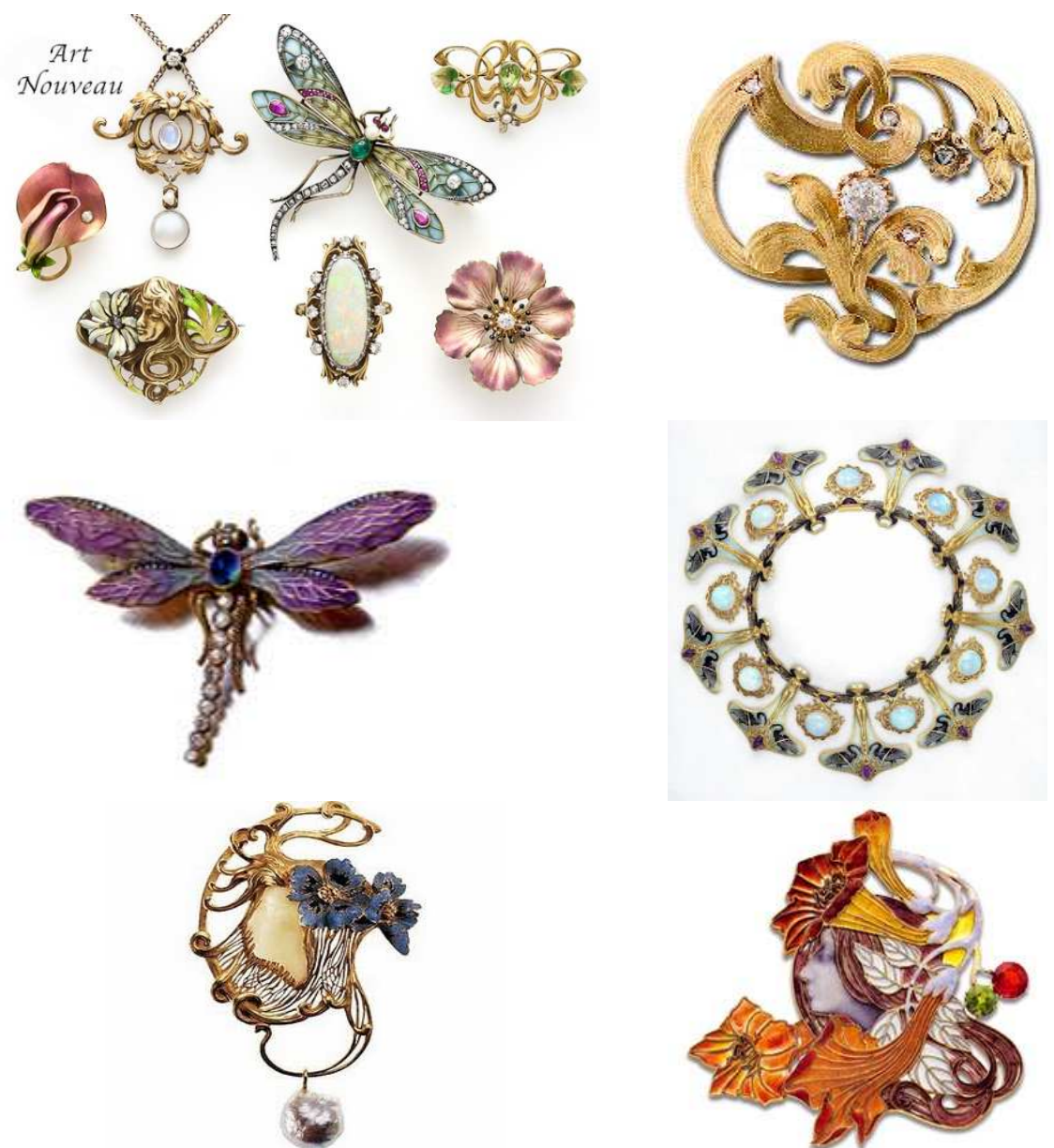

Fonte: Lang Antique and Estate Jewelry (2012), Tread Gold (2012) e Antique Marks (2012)

As joias são símbolos milenares referentes às aspirações e riquezas que adornavam o corpo desde os povos antigos. As técnicas descobertas abriram caminho para a consolidação da joalheria moderna e contemporânea, que hoje é orientada pelos símbolos e culturas que decorrem do processo evolutivo do homem. A joalheria não se define, como antigamente, pelo tipo de metal com que se trabalha. Hoje em dia, não existe uniformidade de estilos, mas sim uma conjunção e uma pequena grande diversidade de materiais e conceitos (CODINA, 2009).

No final do século XIX, o Art Nouveau trouxe mudanças significativas para o campo cultural e artístico. A expressão Art Nouveau surgiu do nome dado por Samuel Bing a sua galeria, pois pretendia que o local transmitisse ideias de inovação e se aliasse as tendências de

ReLAInEP - Revista Latino-America de Inovação e Engenharia de Produção, Curitiba, PR, Brasil, v. 3, n. 4, p. 8-23, 2015. 


\section{ReLAInEP}

arte moderna. Bing contou com a contribuição de vários artistas para realizar os projetos da galeria, que colaboraram para o sucesso do lugar, gerando curiosidade dos parisienses.

Exuberante e expressivo são termos que descrevem com clareza o estilo que, apesar de seu curto período, marcou a história. Esse movimento disseminou-se rapidamente pela Europa e América, recebendo diversas denominações, como Modern Style, Modernismo, Jugendstil, Sezession, Liberty, entre outros.

Ao longo da magnitude de significados, o Art Nouveau atingiu patamar internacional, manifestando características distintas, em vários campos artísticos, como escultura, pintura, arte gráfica, arquitetura, design de interiores, móveis, joias entre outros. Em oposição ao Ecletismo e a era industrial, o Art Nouveau surgiu com a intenção de renovar a arte, privilegiando a forma, a liberdade de criação e a qualidade dos produtos por meio do trabalho artesanal. De acordo com Codina (2000, p. 9), "pela primeira vez valorizou-se, na joalheria, mais a criatividade e imaginação do que os materiais utilizados".

A favor de formas suaves, motivos florais delicados e linhas sinuosas, o tema central do Art Nouveau foi à renovação no campo das artes decorativas e aplicadas. A natureza proporcionava inspiração àqueles que estavam cansados dos elementos tradicionais, e recorriam para o bom gosto, por meio da representação estilizada de formas femininas e elementos da natureza.

Valendo-se da estética Nouveau, as peças serão vazadas, confeccionadas em sua maioria por fios de metal, o que as tornará mais leves e ergonômicas, evitando o desperdício de material e implicando na redução de custos.

A joia deve estabelecer uma relação de conforto, beleza e qualidade, partindo de critérios que dizem respeito à usabilidade e funcionalidade. Para o desenho e criação de anéis, colares, pulseiras e brincos, Mancebo (2008) propõe:

- Na definição do aro de um anel, pode-se considerar uma medida média feminina ( $\operatorname{aros} n^{\circ} 15$ a $\left.n^{\circ} 18\right)$. Porém, para a criação exclusiva, personalizada ou adequações comuns quando da compra de um anel, deve-se medir o dedo da pessoa para qual será feito o projeto/venda, utilizando-se uma aneleira.

- Para braceletes e pulseiras, estas são as medidas padronizadas para cada tipo, considerando a média comercializada:

- bracelete interno redondo, de $60 \mathrm{~mm}$ a $75 \mathrm{~mm}$ o diâmetro;

- bracelete oval aberto, de $45 \mathrm{~mm}$ x $60 \mathrm{~mm}$;

ReLAInEP - Revista Latino-America de Inovação e Engenharia de Produção, Curitiba, PR, Brasil, v. 3, n. 4, p. 8-23, 2015. 


\section{ReLAInEP}

- comprimento de pulseiras para adultos (medida feminina), 180/190 mm.

- Padrões aproximados para:

- Coleiras: $350 \mathrm{~mm}$ a $380 \mathrm{~mm}$;

- Choker: 380 a $400 \mathrm{~mm}$;

- Gargantilhas com pingentes: $420 \mathrm{~mm}$ a 450mm;

- Colares: 500mm a $900 \mathrm{~mm}$ ou mais (1280 para uma volta curta e uma longa).

- Com os brincos, o principal cuidado é relativo ao peso. $\mathrm{O}$ ideal é que este não ultrapasse 10,0g (cada um).

\subsection{Aspectos sociológicos e sustentabilidade do produto}

Para o presente projeto, procurou-se explorar os recursos disponíveis em território brasileiro, como a diversidade de gemas e o capim dourado, valendo-se desses materiais para traduzir a vibração, a alegria e a brasilidade, mesclando etnias.

A criação da coleção de joias do referido projeto tem o design como ferramenta criativa de diferenciação e valorização do produto. Deste modo, abrange à produção de joias com subsídios capazes de torná-la singular, em razão da inserção de materiais que remetem à cultura e diversidade brasileiras, empregando valores da identidade local.

Por outro lado o tema sobre a sustentabilidade (BARBIERI, 2007; (BÉLANGER et al., 2012; ÖZEROL; BRESSERS; COENEN, 2012) é atual e não se refere apenas às necessidades de mercado e sim a uma realidade mundial, que propõe a busca de soluções em relação ao uso desenfreado de recursos naturais que estão causando desequilíbrio no meio ambiente, ameaçando gerações futuras contribuindo para uma sociedade mais saudável.

Desse modo, unindo design e sustentabilidade, pretende-se tornar o produto aceitável capaz de competir no mercado, para que o consumidor descubra e a valorize o produto brasileiro e entenda a necessidade de preservar e utilizar esses materiais de maneira consciente.

ReLAInEP - Revista Latino-America de Inovação e Engenharia de Produção, Curitiba, PR, Brasil, v. 3, n. 4, p. 8-23, 2015. 


\section{ReLAInEP}

\subsection{Aspectos simbólicos da joia}

Nas joias, as mensagens transmitidas aos consumidores se dão primeiramente pela estética. A forma do produto, assim como os materiais, tem a finalidade de se tornar atrativos aos olhos dos consumidores, incitando o desejo de consumo.

Santaella (2003, p.13) corrobora que, "a semiótica é a ciência que tem por objeto de investigação todas as linguagens possíveis que tem por objetivo o exame dos modos de constituição de todo e qualquer fenômeno como fenômeno de produção de significado e de sentido". E faz parte da essência da joia remeter a símbolos e significados de poder e ostentação. Esses conceitos implícitos podem carregar diferentes valores, como, valor cultural e de identidade e, tornando-se relevantes por meio do design.

O papel dos adornos como elementos da cultura material vai além dos requisitos funcionais e técnicos, pois envolve componentes simbólicos, psicológicos e afetivos. De modo que, o significado dos objetos se forma no mundo culturalmente constituído. E para tornar-se inerente aos bens de consumo, precisa desengajar-se do mundo e transferir-se para o bem, pois os produtos são culturalmente inseridos.

O design pode servir de instrumento desta transferência de simbolismo as joias tais como as artes, o artesanato entre outros artefatos que visam dar existência concreta e autônoma a ideias subjetivas, age na instância da atribuição de significados e ao projetar, o designer pode atribuir significados aos adornos que vão muito além da funcionalidade.

O significado do artefato para o usuário não se reduz ao seu funcionamento e seria mais adequado falar de 'funções' do objeto do que de 'função', principalmente no que diz respeito à sua inserção em um sistema de produção, circulação e consumo de mercadorias.

Denis (2003) corrobora que entra em consideração uma série de outras "funções", dentre as quais podemos destacar o contexto de uso, a comodidade, o conforto, o gosto, o prazer, a inserção social e a distinção. A joia carrega, também, concepções e valores resultantes da leitura do designer sobre a cultura e a sociedade a que pertence. Alguns tipos de mensagens transmitidas pelos adornos podem variar entre sua própria constituição; funções práticas; modos de uso; valores estéticos.

ReLAInEP - Revista Latino-America de Inovação e Engenharia de Produção, Curitiba, PR, Brasil, v. 3, n. 4, p. 8-23, 2015. 


\section{ReLAInEP}

\section{METODOLOGIA}

Para o presente projeto, foi empregada uma metodologia própria, com base nos métodos defendidos por Bernand Löbach (2000) e Mike Baxter (1998). Segundo Löbach (2000), o designer, como produtor de ideias, deve valer-se da criatividade, tanto na parte estética quanto na parte formal, no desenvolvimento de um produto que traga benefícios e atenda as necessidades do usuário.

Para Baxter (1998), o planejamento de um produto abrange vários critérios e interesses, como materiais, processos e diferentes possibilidades que resultarão em uma solução viável.

Na primeira fase do projeto, foi realizada a análise da necessidade e a análise da relação social. Essas identificam a possível aceitação do produto no mercado e as pessoas que estariam interessadas na solução do problema. Permite entender, também, a interação do usuário com o produto, a fim de definir o tipo de público e os benefícios que este produto proporcionará a esses indivíduos. As análises referenciadas definem o público e as necessidades a serem sanadas. A partir disso, é feita a análise de mercado, na qual são avaliados os produtos encontrados no mercado atual. Essa análise permite identificar os pontos deficientes dos produtos concorrentes, estabelecendo o que poderá ser melhorado, permitido a criação de um produto diferenciado.

O conhecimento da estrutura do produto e sua complexidade são possíveis a partir da análise estrutural, na qual se identifica o que poderá ser melhorado em beneficiamento mediante o uso. É essencial a observação técnica das diferentes funções do produto, realizada por meio da análise da função. Valendo-se da metodologia de Baxter (1998), a análise morfológica permite o entendimento dos mecanismos, da forma, dos acabamentos, dos elementos e componentes que determinam o funcionamento adequado do produto. Após a realização das análises necessárias ao projeto, inicia-se a etapa de geração de alternativas, seguida da etapa de avaliação de alternativa, na qual são selecionadas as propostas mais aceitáveis e viáveis que atendam as necessidades encontradas.

Seguindo os métodos de Baxter (1998), com os esboços definidos, inicia-se a configuração e projeto detalhado, que consiste nos desenhos técnicos que mostram como será a estrutura, funcionalidade e as medidas do produto. Com esses itens resolvidos, dá-se início ao processo de modelagem em um programa gráfico (Rhinoceros), que mostrará a aparência visual do produto tridimensionalmente, com os devidos materiais e acabamentos. Após esta

ReLAInEP - Revista Latino-America de Inovação e Engenharia de Produção, Curitiba, PR, Brasil, v. 3, n. 4, p. 8-23, 2015. 


\section{ReLAInEP}

etapa, o projeto é produzido, respeitando-se as medidas reais, assim como os materiais e processos sugeridos no mesmo. A coleção agrega ao tema Art Nouveau um apelo nacionalista brasileiro na escolha da matéria-prima com as gemas brasileiras e o capim dourado.

\subsection{Definição do Problema}

Por meio das análises realizadas, constatou-se que, apesar do crescimento do setor de joias brasileiro, o produto nacional no mercado interno é pouco valorizado, havendo maior prioridade ao produto importado.

Desta maneira, avaliou-se, em sua totalidade, a importância de desenvolver um produto visando a diversidade gemológica encontrada no Brasil assim como o capim dourado, que é um produto típico do Brasil, usado somente no artesanato e na confecção de bijuterias.

Para isso, reafirma-se a intenção de valorizar o produto nacional, remetendo aos símbolos de identidade brasileira, mostrando que os recursos naturais alternativos, situados em solo brasileiro, encontram forte identificação com as cores, a biodiversidade e alegria do povo brasileiro. Acredita-se que o investimento na mistura desses materiais, para a criação de uma coleção, contribuirá com o design de joias brasileiro, para que este possa interferir no mercado, mostrando seu potencial, partindo de critérios de qualidade, funcionalidade, estética e identidade, atendendo às necessidades de mercado.

No projeto, são abordados aspectos ergonômicos, respeitando a antropometria feminina, que serviram de parâmetro. A ergonomia terá relação com as formas arredondadas, o peso e o conforto, visto que para o projeto as gemas serão utilizadas: os aspectos funcionais relacionados à fácil usabilidade; a estética, por meio do tema escolhido como inspiração, na qual as linhas sinuosas e orgânicas darão leveza e elegância às peças, assim como os acabamentos sugeridos e os materiais citados, além do valor simbólico que remete à identidade.

Quanto aos impactos ambientais identificados, trata-se de uma realidade e necessidade de mercado com relação ao consumidor consciente, além de considerar a otimização do processo produtivo para minimizar erros, reduzir o desperdício de material e alcançar o máximo de qualidade na execução das joias.

ReLAInEP - Revista Latino-America de Inovação e Engenharia de Produção, Curitiba, PR, Brasil, v. 3, n. 4, p. 8-23, 2015. 


\section{ReLAInEP}

\subsection{Materiais e Processos}

Para o presente projeto, são propostas algumas alternativas para reduzir os resíduos gerados pelos processos utilizados no setor joalheiro, pois o corte e polimento produzem resíduos que, descartados de maneira incorreta, causam impactos ambientais. Sugere-se o processo de recuperação de metais como ouro e prata. O processo de recuperação de resíduos industriais consiste em recolher e analisar todos os materiais provenientes do lixo, do polimento, da lixa, do uniforme, do carpete da varredura do chão, etc., sendo que a purificação desse material é feita por meio químico.

Com relação aos materiais e processos, a criação de uma joia envolve várias etapas. Para que possa ser produzida, é necessário o conhecimento sobre os diferentes materiais e processos. Na produção, os metais não são utilizados em estado puro, pois são acrescentadas ligas de outros metais para que estes se tornem resistentes mediante aos processos de fabricação e posteriormente ao uso. Para o presente projeto, propõe-se a utilização dos seguintes materiais e processos:

O ouro $(\mathrm{Au})$ é conhecido desde a antiguidade. No Brasil, a liga de ouro $18 \mathrm{k}$ é a mais usada e sua composição refere-se a outros metais responsáveis pela sua cor final. O ouro amarelo permite que várias colorações sejam atingidas, a partir da inclusão de ligas de outros metais na proporção adequada. $\mathrm{O}$ ouro branco é atingido quando a este é adicionado o paládio, responsável pela cor branca do metal.

A prata (Ag) é um metal precioso de alto brilho e de cor branca que possui grande reflexão de luz. Para misturar ao metal, sugere-se o uso do capim dourado, que é um produto típico do Brasil e foi descoberto pelos Índios no norte de Goiás, onde atualmente é o estado do Tocantins. Os índios trançavam e costuravam o capim usando espinhos como agulha e faziam seus utensílios domésticos, como gamelas, cestos, bacias, tigelas, potes, etc. Na atualidade, os fios do capim dourado são tratados e utilizados na confecção de diversos objetos, inclusive na joalheria.

Serão utilizadas gemas brasileiras, o que torna o design de joias reconhecido, pois a partir da utilização da matéria-prima local cria-se uma identidade nacional para a joalheria brasileira. Os aspectos simbólicos no design de joias também foram considerados para a criação, pois além de proporcionar funcionalidade, os objetos produzem sentimentos e emoções.

ReLAInEP - Revista Latino-America de Inovação e Engenharia de Produção, Curitiba, PR, Brasil, v. 3, n. 4, p. 8-23, 2015. 


\section{ReLAInEP}

\subsection{Conceito}

A coleção de joias inspirada na estética Art Nouveau se propõe em três linhas: Lé Metropolitain, Petit Palais e Villa Majorelle e baseia-se no conceito de identidade, para que transmita os ideais de valorização do produto nacional, ressaltando sua importância. A Figura 2 mostra a coleção 1 (Lé Metropolitain).

\section{Figura 2 - Coleção Lé Metropolitain}
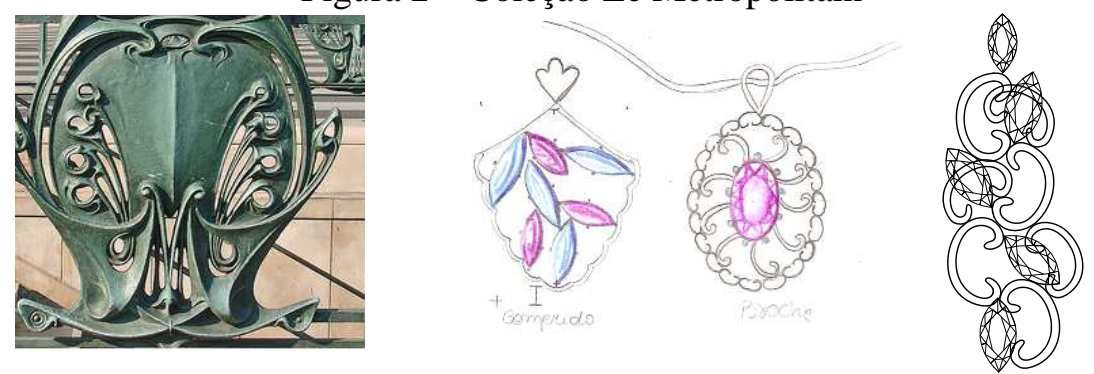

Fonte: Elaborado pelo autor

A Linha Lé Metropolitain desenvolvida para a coleção remete as formas sinuosas e elegantes do estilo Art Nouveau observadas no detalhe arquitetônico da estação de metrô em Paris - Lé Metropolitain, complementada com as gemas brasileiras Ametista e Topázio Azul. A Figura 2 mostra a coleção 2 (Petit Palais).

Figura 3 - Coleção Petit Palais
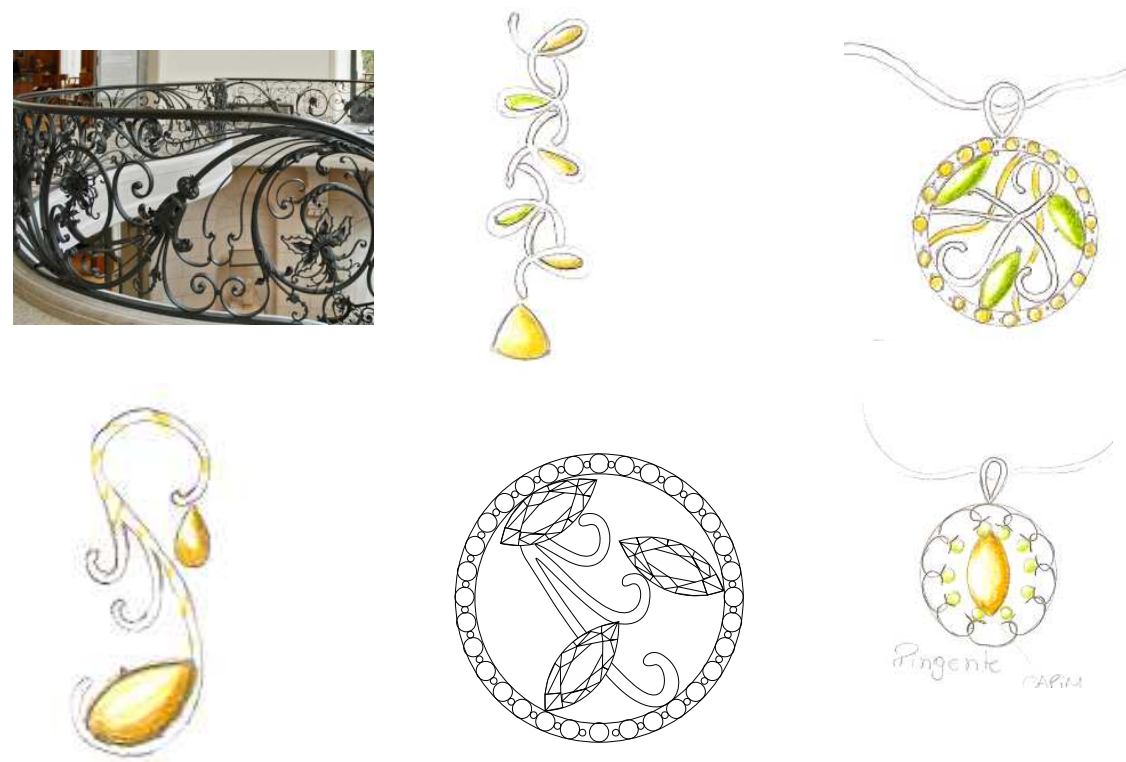

Fonte: Elaborado pelo autor

ReLAInEP - Revista Latino-America de Inovação e Engenharia de Produção, Curitiba, PR, Brasil, v. 3, n. 4, p. 8-23, 2015. 


\section{ReLAInEP}

A Linha Petit Palais desenvolvida para a coleção de joias valoriza as formas curvas e leves da escadaria de ferro do Palácio Petit Palais e complementadas com as gemas brasileiras com o Citrino, Topázio Imperial e a Praziolita. As joias serão incrementadas com o capim dourado que além de valorizar a matéria prima nacional atende a uma tendência de mesclar materiais simples as joias.

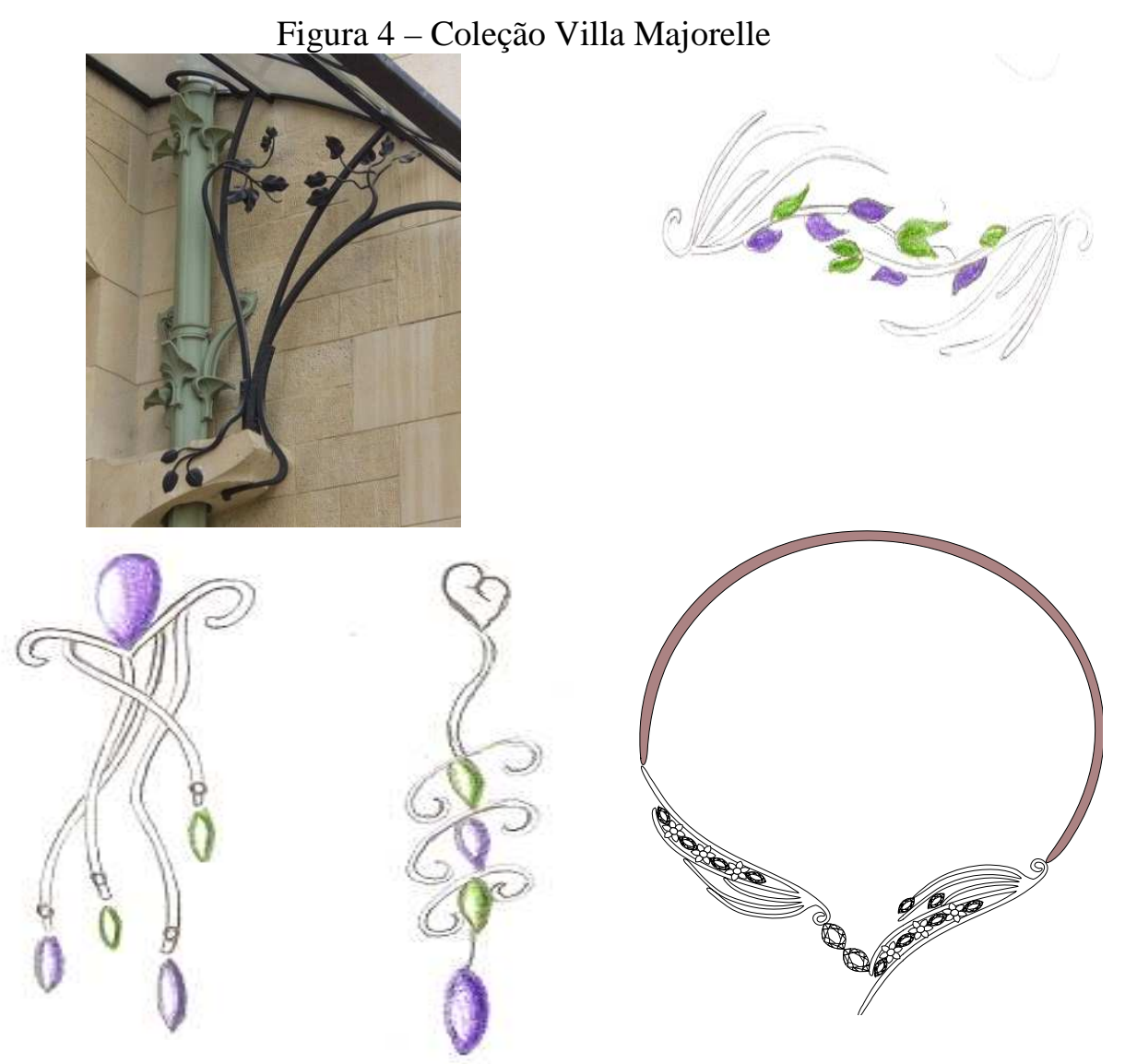

Fonte: Elaborado pelo autor

A terceira linha conta com os ornamentos da Villa Majorelle. Esses elementos serão traduzidos para as peças, por meio das curvas assimétricas e motivos florais Figura3. A turmalina Paraíba e a esmeralda são as gemas sugeridas para essa linha.

Para as formas, busca-se o conceito nos elementos arquitetônicos Art Nouveau: Linhas orgânicas e curvilíneas; Formas estilizadas da natureza.

$\mathrm{Na}$ contemporaneidade busca-se: design com mistura de materiais e gemas brasileiras e o Capim dourado (Identidade).

ReLAInEP - Revista Latino-America de Inovação e Engenharia de Produção, Curitiba, PR, Brasil, v. 3, n. 4, p. 8-23, 2015. 


\section{ReLAInEP}

\section{CONCLUSÃO}

Por meio das análises realizadas, constatou-se que, apesar do crescimento do setor de joias brasileiro, o produto nacional no mercado interno é pouco valorizado, havendo maior prioridade ao produto importado.

Desta maneira, avaliou-se, em sua totalidade, a importância de desenvolver um produto visando a diversidade gemológica encontrada no Brasil assim como o capim dourado, que é um produto típico do Brasil, usado somente no artesanato e na confecção de bijuterias.

Para isso, reafirma-se a intenção de valorizar o produto nacional, remetendo aos símbolos de identidade brasileira, mostrando que os recursos naturais alternativos, situados em solo brasileiro, encontram forte identificação com as cores, a biodiversidade e alegria do povo brasileiro. Acredita-se que o investimento na mistura desses materiais, para a criação de uma coleção, contribuirá com o design de joias brasileiro, para que este possa interferir no mercado, mostrando seu potencial, partindo de critérios de qualidade, funcionalidade, estética e identidade, atendendo às necessidades de mercado.

No projeto, foram abordados aspectos ergonômicos, respeitando a antropometria feminina, que serviram de parâmetro. A ergonomia terá relação com as formas arredondadas, o peso e o conforto, visto que para o projeto as gemas serão utilizadas: os aspectos funcionais relacionados à fácil usabilidade; a estética, por meio do tema escolhido como inspiração, na qual as linhas sinuosas e orgânicas darão leveza e elegância às peças, assim como os acabamentos sugeridos e os materiais citados, além do valor simbólico que remete à identidade.

Quanto aos impactos ambientais identificados, trata-se de uma realidade e necessidade de mercado com relação ao consumidor consciente, além de considerar a otimização do processo produtivo para minimizar erros, reduzir o desperdício de material e alcançar o máximo de qualidade na execução das joias.

Portanto, busca-se uma coleção de joias com formas orgânicas leves em harmonia com o tema escolhido, fazendo referência ao conceito de identidade, passíveis de produção artesanal e industrial, nos quais existe campo para novas ideias e a mistura de materiais. $\mathrm{E}$ uma coleção que se insere no mercado nacional para competir no cenário globalizado e com referenciais simbólicos que resgatam a beleza e encantamento do estilo arquitetônico da Arte

ReLAInEP - Revista Latino-America de Inovação e Engenharia de Produção, Curitiba, PR, Brasil, v. 3, n. 4, p. 8-23, 2015. 


\section{ReLAInEP}

Nova. Bem como a mescla com os produtos brasileiros como as gemas e o capim dourado numa concepção estética contemporânea.

\section{REFERENCIAS}

ANTIQUE MARKS. René Lalique Glass. Disponível em: <http://www.antiquemarks.com/rene-lalique.html> Acesso em: 23 de out./2012.

BARBIERI. Jose Carlos. Desenvolvimento e meio ambiente: as estratégias de mudanças da agenda 21. Petrópolis, RJ: Vozes, 1997.

BAXTER, Mike. Projeto de produto: guia prático para o design de novos produtos. 2. ed. São Paulo: Edgard Blücher, 1998.

BÉLANGER, V. et al. Development of agri-environmental indicators to assess dairy farm sustainability in Quebec, Eastern Canada. Ecological Indicators, v. 23, p. 421-430, 2012.

CODINA, Carles. A joalharia. Lisboa, PT: Estampa 2000.

DENIS, Dutton. JERROLD, Levinson. The Oxford Handbook of Aesthetics. Ed.

"Authenticity in Art" (Oxford University Press) (2003).

IBGM, Instituto Brasileiro de Gemas e Metais Preciosos. Preview Design de Joias e Bijuterias. SEBRAE, ApexBrasil, 2011.

IIDA, Itiro. Ergonomia: projeto e produção. São Paulo: Edgard Blücher, 1990.

LANG ANTIQUE AND ESTATE JEWELRY. Disponível em: <http://www.langantiques.com/>. Acesso em: 23 de out./2012.

LEDEL, Fabiane Lima. Elementos arquitetônicos do Estilo Art Nouveau como referencial para a criação de uma Coleção de joias. 2011. 104f. Trabalho de Conclusão de Curso (Curso de Design). Centro Universitário Franciscano (UNIFRA), Santa Maria, 2011.

LÖBACH, Bernd. Design industrial: bases para a configuração dos produtos industriais. Rio de Janeiro: Edgard Blücher, 2000.

MANCEBO, Liliane de Araújo. Guia prático para o desenho de joias, bijuterias e afins. Novo Hamburgo: Feevale, 2008.

MANZINI, Ezio. A matéria da invenção. Lisboa: Centro Português de Design, 1993.

MARKOWITZ, Y.J.; WARD, S. The innovative techniques and unusual materials of art nouveau jewelry. Magazine Antiques, v. 174, n. 1, p. 56-63, 2008.

ReLAInEP - Revista Latino-America de Inovação e Engenharia de Produção, Curitiba, PR, Brasil, v. 3, n. 4, p. 8-23, 2015. 


\section{ReLAInEP}

ÖZEROL, G.; BRESSERS, H.; COENEN, F. Irrigated agriculture and environmental sustainability: An alignment perspective. Environmental Science and Policy, v. 23, p. 5767, 2012.

SANDROLINE, $\mathrm{F}$ et al. Materials and technologies in Art Nouveau architecture: Façade decoration cases in Italy, Portugal and Poland for a consistent restoration. Informes de la Construccion, v. 63, n. 524, p. 5-11, 2011.

SANTAELLA, Lúcia. O que é semiótica. São Paulo: Brasiliense, 2003.

SHUMANN. Walter. Gemas do mundo. 2. ed. Rio de Janeiro, 2003.

SIMONI, C.; RABINO, S.; ZANNI, L. Italian and Indian gold and jewelry SMEs, marketing practices in the USA: A comparative case study. Journal of Small Business and Enterprise Development, v. 17 n. 3, p. 403-417, 2010.

TREAD GOLD. Artist in Residence: Lalique. Disponível em: <http://treadgoldcollection.blogspot.com.br/2010/09/lovely-lalique.html> Acesso em: 23 de out./2012.

ReLAInEP - Revista Latino-America de Inovação e Engenharia de Produção, Curitiba, PR, Brasil, v. 3, n. 4, p. 8-23, 2015. 